\title{
Neuropsychological Complications of HIV Disease and Substances of Abuse
}

\author{
${ }^{1}$ Lisa R. Norman and ${ }^{1,2,3}$ Anil Kumar \\ ${ }^{1}$ AIDS Research Program and ${ }^{2}$ Laboratory of Viral Immunology, Department of Microbiology \\ Ponce School of Medicine, Ponce, PR 00732; Division of Pharmacology, School of Pharmacy, University \\ of Missouri, Kansas City, MO 64108
}

\begin{abstract}
In the last decade, it has become increasingly apparent that neuropsychological deficits and impairments are associated with HIV infection. Given that antiretroviral therapies have extended the life expectancy of HIV-infected persons, it becomes critical to focus on the physical and mental health of these patients. Understanding the neuropsychology of HIV disease can provide insight into improving mental health, functional capacity and overall quality of life for persons living with HIV/AIDS. Furthermore, clinicians may be better able to assist patients to manage their symptoms, thereby increasing the number of patients who are able to successfully maintain difficult treatment schedules. In addition, it is equally important to understand the potentially exacerbating effects of various factors. One such factor is substance abuse, which has been associated with various neuropsychological impairments, irrespective of the substance of abuse. Therefore, a more complete understanding of the effects of substance abuse on the progression of impaired cognitive processes and functioning can allow for an enhanced evaluation and management of those patients who live with HIV disease and who suffer from substance abuse disorders. As such, the present paper provides an overview of the neuropsychology of HIV and substance abuse, as well as of the available research that has examined the potential interaction effects between HIV disease and substance abuse. The implications of the findings as well as directions for future research are discussed.
\end{abstract}

Key words: HIV, AIDS, neuropsychology, substance abuse

\section{INTRODUCTION}

HIV/AIDS continues to be a global problem, with more than 40 million living with the disease reported at the end of $2005^{[1]}$ In view of the fact that combination antiretroviral therapy has extended the life expectancy of most HIV-infected individuals, it becomes critical to focus on the physical and mental health of these patients. Therefore, there has been great emphasis, in the recent past, on neuropsychological studies (including the associated complications) among HIVinfected persons.

Prevalence of neuropsychological complications increases with disease progression and the presence of impairments is associated with earlier mortality. As such, understanding the neuropsychology of HIV disease can provide insight into improving mental health, functional capacity and overall quality of life for persons living with HIV/AIDS. Furthermore, by comprehending neuropsychological complications, clinicians may be better able to help HIV-infected patients manage their symptoms, which, in turn, may increase the number of patients who are able to maintain difficult treatment schedules ${ }^{[2]}$.

In addition, a comprehension of the scope of the neuropsychology of HIV disease, including the potentially exacerbating effects of substance abuse on related cognitive processes and functioning, is important for the enhanced evaluation and management of patients living with both HIV/AIDS and substance abuse disorders. The co-occurrence of HIV disease and substance abuse disorders may lead to compounded medical and psychiatric complications, difficulties with HIV medication compliance and poorer treatment outcomes (beyond those associated with HIV disease alone). With a greater understanding of the etiology and course of the neuropsychological consequences of HIV disease and substance abuse, new avenues for prevention and treatment can be developed. Comprehensive neuropsychological assessments that consider both HIV disease and substance abuse may allow for the early detection of complications before irreversible neuronal damage occurs, which may facilitate the development and implementation of appropriate and targeted therapies and treatment.

However, in order to develop and implement appropriate and effective therapies and treatments for those living with both HIV disease and substance abuse disorder, it is imperative to be cognizant of research that has been conducted in the area. As such, this review examines the research in a number of areas, including the neuropsychology of HIV disease, the neuropsychology of substance abuse and the potential

Corresponding Author: $\quad$ Lisa R. Norman, Ph.D., AIDS Research Program, Ponce School of Medicine, Tel: PR 00732 
interaction of HIV disease and substance abuse. In addition, implications for future research are discussed. The neuropsychology of HIV/AIDS: Neuropsychology can be defined as applied neuroscience and is broadly focused on understanding brain-behavior relationships that may be impacted by brain injury or disease, such as cognitive, sensorimotor, emotional and general adaptive capacities of the individual $^{[3,4]}$. The discipline encompasses both neurocognitive and neurobehavioral processes. Neurocognitive processes include perceptual abilities, abstraction and conceptualization, executive functions, perceptual motor integration, learning, remembering and attention. Neurocognitive functioning can also be described in terms of speed, efficiency and flexibility. Neurobehavioral processes are broader in scope, including neurocognitive processes and functioning as well as other brain-mediated behaviors, such as mood and affect, personality, coping and temperament. It is theorized that significant changes in the neurocognitive functioning are the most explicit measures of underlying pathologic changes in the brain, while neurobehavioral changes can occur for many nonneuropathological reasons (e.g., change in mood brought on by unhappy news $)^{[5]}$.

Neuropsychological deficits and disorders are common in persons infected with HIV. When HIV enters the central nervous system, disturbances in neurocognitive functions occur and can vary, not only by disease stage, but also by disease markers such as viral loads in the cerebrospinal fluid (CSF), CD4 counts, the presence of opportunistic infections, as well as antiretroviral medications ${ }^{[6-8]}$. The central nervous system can be impacted by HIV in a number of ways. A primary neurogenic disorder results when HIV enters the brain and produces cognitive, behavioral and neurological abnormalities. A secondary disorder results in neurobehavioral complications associated with the progression of immunodeficiency. As HIV disease progresses toward the later stages of AIDS, it is possible that a combination of primary and secondary neurogenic disorders will coexist ${ }^{[9]}$.

For the purpose of categorizing neurocognitive complications, a three-tiered classification has been developed: asymptomatic neuropsychological impairment; mild neurocognitive disorder; and HIVassociated dementia. Asymptomatic neuropsychological impairment is characterized by changes in cognitive function that do not appear to interfere with day-to-day functioning but must include mild impairments in two different cognitive areas. Mild neurocognitive disorder, also known as minor cognitive motor disorder, includes impairments in at least one area of life functioning and in at least two different cognitive areas. HIV-associated dementia exists when there is impairment in at least two and usually more, cognitive areas; the impairment must be of sufficient severity to significantly interfere with multiple areas of life functioning. The onset of dementia is usually a poor prognostic sign in HIV disease and is often predictive of approaching mortality. However, a fourth classification or stage recently has been included: neuropsychological deficits. This stage is categorized as pre-asymptomatic neuropsychological impairment with some abnormality or change in one cognitive ability area ${ }^{[5]}$.

Usually, HIV-infected individuals will develop some degree of neuropsychological dysfunction, with more pronounced impairment emerging in later HIV disease stages. Since the introduction of HAART, the incidence of HIV dementia has decreased by approximately $50 \%{ }^{[10]}$. While the incidence of dementia has decreased significantly and patients are living longer as a result of HAART, prevalence of less serious HIV-associated neurological impairments may be increasing and can occur even during potent antiretroviral treatment ${ }^{[11]}$.

The neuropsychology of substance abuse: In addition to HIV-related disease characteristics, a number of biological, social and psychiatric factors can affect neuropsychological performance. Demographic factors such as age, education, sex, ethnicity, premorbid and co-morbid conditions (including a history of CNS disease and/or psychiatric illness as well as systemic illness) have all been found to be independently associated with neuropsychological functioning ${ }^{[12]}$. However, one of the major risk factors associated with neuropsychological impairment is substance abuse. It is estimated that between 30 and $80 \%$ of substance abusers show mild to severe impairment ${ }^{[13]}$.

Substances of abuse fall into a number of categories: opiates (e.g., heroin); stimulants (e.g., cocaine, methamphetamine); sedatives (e.g., barbiturates, benzodiazepines); cannabis (e.g., marijuana); hallucinogens (e.g., LSD); inhalants (e.g., glue, gasoline); and alcohol, among others. While all substances of abuse act in the brain to produce their euphoric effects, substance use and abuse can also cause brain changes that may lead to cognitive impairment in numerous areas, including memory, attention, decision-making, executive functions, cognitive flexibility and motor. However, neurological complications vary significantly depending both upon the substance of abuse and upon which area(s) of the brain has been subsequently been affected ${ }^{[14-16]}$.

Research with cocaine users has found cognitive impairments in the areas of attention, learning, memory, executive functions and cognitive flexibility ${ }^{[17-22]}$. These effects are also present among those who consume the drug in its smokeable form--crack cocaine--and may be even more pronounced in these users compared to cocaine users who do not smoke the drug ${ }^{[23-26]}$.

Methamphetamine usage has been reported to be associated with the impairment of dopamine function (even after several years of discontinuance) and is known to affect several brain functions, including 
pleasure, mood and movement. Abusers of the drug have been found to be cognitively impaired the areas of attention, psychomotor speed, learning, memory, executive functions and decision-making. Some may even suffer loss of spontaneous movement, similar to Parkinson's disease ${ }^{[27-29]}$.

Opiates have been found to induce impairments in the areas of attention, information processing, problem solving, coordination, working memory and psychomotor speed and performance ${ }^{[30-34]}$. Furthermore, research indicates that opiate users in methadone maintenance may have significantly more neuropsychological impairment than those in treatment, suggesting that methadone exacerbates cognitive dysfunction in opiate users ${ }^{[35]}$.

Previous research has found neuropsychological impairments, particularly in the area of memory, attention and learning tasks, in MDMA (methylenedioxymethaphetamine) users. Additional research has also found cognitive impairment associated with other hallucinogenic drugs such as ketamine and psilocybin ${ }^{[36,-41]}$.

Past research has found that marijuana users had impaired cognitive functioning in the areas of memory and attention, executive functions and cognitive flexibility and increasing frequency of use was associated with delayed information processing ${ }^{[20,42-44]}$. Furthermore, research examining the interaction effects of MDMA and marijuana revealed that MDMA, when used in combination with marijuana, produced psychopathological manifestations than MDMA used alone $^{[45,46]}$.

A loss of synapses, resulting from alcohol abuse, can cause some of the abnormal movements often seen in alcohol abusers, such as unsteady gait, tremors and lack of coordination. In addition, other deficits have been associated with alcohol use and abuse, including impairments in the following cognitive functions: memory, verbal learning, abstract thinking, problemsolving, perceptual analysis and synthesis, speed of information and efficiency, as well as perceptual motor skills ${ }^{[24,47-53]}$. Also, research found that when compared to cocaine, alcohol had more negative effects on attention and executive functioning ${ }^{[22]}$.

Noting that both HIV disease progression and substance use and abuse can cause serious neurological problems--including neuropsychological impairments-it is important to examine the relationships among HIV disease, substance use and abuse and neuropsychological complications. Specifically, we will examine the relevant research to determine whether there appears to be an interaction effect of HIV and the abuse of substances that accelerates the progression of neuropsychological complications among HIV-infected persons who are advancing toward full-blown AIDS.

Neuropsychological complications associated with HIV/AIDS and substance abuse: While the research examining neuropsychological complications of HIV/AIDS as well as among substance users is quite extensive, relatively little research has been done examining the interaction effect of HIV disease and substance use on neuropsychological functioning. A number of studies have examined neuropsychological functioning among substance abusers, with some samples consisting of all substance users among HIVseropositive and/or HIV seronegative persons ${ }^{[54-57]}$. However, these studies do not allow for an examination of the interaction effect between HIV disease and substance abuse on neurological functioning. For the studies that are able to examine the potential interaction effects of HIV disease and substance abuse, the findings presented below are categorized by drug type.

Stimulants: Several studies have examined the HIV disease/substance use interaction, the vast majority has focused on HIV and methamphetamine use. In one study of 75 individuals, a neuropsychological battery of tests was administered to and examined separately for four groups of individuals with different levels of HIV status and a varying history of methamphetamine use (HIV+/METH+, HIV+/METH-, HIV-/METH+, HIV/METH-). Upon examining the test results, it was found that the groups were significantly different with respect to global cognitive impairment; the HIV+/METH+ group demonstrated the highest rate of impairment (65\%), followed by the HIV-/METH+ group (45\%), the $\mathrm{HIV}+/ \mathrm{METH}$ - group (43\%) and the HIV-/METHgroup $(20 \%)^{[58]}$. Another study--using a larger sample $(n=200)-$-found the same significant differences between the same sub-groups; the HIV+/METH+ group had the highest rates of global neuropsychological impairment ${ }^{[59]}$. Trend analyses for median global deficit scores (GDS) from the same sample were also conducted. Groups with only one risk factor (either HIV or substance use) were combined in order to assess differing trends between the groups with two risk factors, one risk factor, or no risk factors. The trend analyses results for the GDS, as well as for the individual functions of learning, recall and motor skills, indicated a monotonic trend among the three groups and hence an additive risk of the presence of the two risk factors. Rates of neuropsychological impairment by group were $58 \%$ for the group with two risk factors, $39 \%$ for the group with one risk factor and $18 \%$ for the group with no risk factors ${ }^{[60]}$. Another study of 367 individuals also found the same trend, with HIV+/METH+ individuals having the highest rates of neuropsychological impairments (54\%), followed by the HIV-/METH+ group (42\%), the HIV+/METHgroup $(34 \%)$ and the HIV-/METH- group $(25 \%)^{[61]}$. This study revealed as well that neuropsychological impairment independently predicted patients' assessments of their own cognitive functioning inventory (PAOFI) for both groups of 
methamphetamine users, including both HIVseropositive and HIV-seronegative individuals, suggesting no significant effect of HIV status on PAOFI scores.

One study examined measures of total learning and short delay free recall among a sample of 52 individuals, including subgroups, based on HIV status and methamphetamine abuse. Significant differences emerged, with a stair-step effect being observed; as had been seen in prior studies, the HIV+/METH+ group performed worst, followed by the HIV-/METH+ group, the HIV+/METH- group and the HIV-/METHgroup $^{[62]}$. In addition, levels of CSF quinolinic acid showed a stair-step increase, with the HIV+/METH+ group showing the highest levels. Previous research has found that elevated concentrations of CSF quinolinic acid may cause regional brain atrophy and neuronal damage to structures that mediate critical cognitive functions ${ }^{[63]}$.

Other studies examining the interaction effect of HIV and methamphetamine use investigated cerebral structures and metabolites in the brain. Study data from 103 individuals, combined into the same four groupings as described above, revealed significant correlations between reductions in hippocampal volume and increasing neurocognitive impairments in the $\mathrm{HIV+/METH+} \mathrm{group.} \mathrm{However,} \mathrm{neither} \mathrm{the} \mathrm{cortical}$ volumes nor the basal ganglia volumes showed any association with neurocognitive impairment for this group, suggesting an HIV disease/drug interaction for some areas in the brain but not others ${ }^{[27]}$. A study of 119 individuals, also grouped into the same four categories, revealed lower levels of metabolites, specifically $\mathrm{N}$-acetylasparate (NAA), in the frontal white matter of HIV-seropositive subjects, regardless of their drug status, suggesting no exacerbated drug effect $^{[64]}$. NAA is a putative marker of neuronal integrity and can be related to neuropsychological functioning.

Several other studies have examined the interaction between HIV disease and substance use/abuse with other stimulants. In one study, individuals who were dependent on methamphetamine, cocaine, or both (STIM+) were examined by HIV status, with 254 individuals from a previous study (who were not dependent on these substances) being used as control subjects. Comprehensive neuropsychological testing revealed an increasing stair-step effect, with $13 \%$ of the HIV-seronegative persons with no stimulant dependence having neurological impairments, compared to $39 \%$ in the HIV+/STIM- group, $62 \%$ in the HIV-/STIM+ group and $71 \%$ in the HIV+/STIM+ group. The presence of stimulants in the urine was also associated with a heightened rate of impairment. When those participants whose urine tested positive for drugs were excluded from the analyses, the rates of impairment were $38 \%$ for those in the HIV-/STIM+ group and $71 \%$ for those in the HIV+/STIM+ group, suggesting an interaction effect ${ }^{[65] .}$ A recent study of 40 HIV-seropositive individuals (12 non-drug users and 17 stimulant users, which included cocaine and/or methamphetamine) examined sustained attention. Groups were compared on overall performance variables, as well as patterns of performance across time. Compared to the non-drug users, stimulant users showed a gradual increase in reaction time variability and omission errors, suggesting that recent stimulant use among $\mathrm{HIV}$-infected persons adversely affects sustained attention $^{[66]}$.

One study examined the additive effects of HIV infection and stimulant dependence on frontostriatal circuitry, specifically measuring NAA, choline and myo-inositol ${ }^{[67]}$. Increases in choline may reflect cell membrane degradation while myo-inositol is found primarily in glial cells and its increase is also associated with membrane breakdown. It is commonly elevated in individuals with neurodegenerative diseases such as Alzheimer's ${ }^{[67-69]}$. Twenty individuals were categorized into four groups: seven $\mathrm{HIV}+/ \mathrm{STIM}+$, five HIV+/STIM-, three HIV-/STIM+ and five HIV-/STIM- Analyses revealed a significant stair-step effect in levels of NAA in the anterior cingulate gyrus between the groups, with the HIV+/STIM+ group demonstrating the lowest level, followed by the HIV+/STIM- group, the HIV-/STIM+ group and the HIV-/STIM- group. No significant effects of HIV and stimulant dependence on levels of choline and myo-inositol emerged.

One study examined both independent and interactive effects of HIV disease and cocaine on neuropsychological performance in a sample of 237 gay and bisexual, urban-dwelling African American men ${ }^{[70]}$. Impairments were found to be higher in symptomatic seropositive individuals compared to both asymptomatic seropositive and seronegative individuals. Moderate to heavy recent cocaine use was also associated with slower psychomotor speed. However, no interaction of HIV disease status and cocaine emerged for any neuropsychological performance domains.

Marijuana: With respect to neuropsychological complications associated with marijuana and HIV, only one study was identified that examined the interaction effect of these two risk factors. Neurological testing, intelligence, depression and anxiety were measured in 288 individuals (74 HIV seronegative, 127 HIVseropositive-asymptomatic and 87 HIV-seropositivesymptomatic). Marijuana use was dichotomized: those who reported having used less than once per month over the previous year were categorized as a no/minimal-use group with the remaining persons categorized as a frequent-use group ${ }^{[71]}$. Results revealed a significant interaction effect for HIV disease and marijuana use with respect to overall impairment score-the difference between the no/minimal-use group and frequent-use group was greatest among 
subjects with symptomatic HIV infection. When individual cognitive functions were examined, a significant effect emerged for delayed memory, with the impact of marijuana use being progressively greater in relation to increasingly severe HIV disease.

Alcohol: Research examining neurological impairments revealed significant interaction effects between HIV status and alcohol use/abuse. In one study, 268 adults were grouped by HIV status and level of alcohol use (light/non-drinkers vs. chronic drinkers). Light/nondrinkers (LD) were operationally defined as participants with lifetime average consumption of fewer than or equal to 45 (35 for women) standard alcoholic drinks per month without past or current alcohol dependence or significant periods of drinking more than 45 drinks per month. Classification as a heavy drinker was based on self-report of an average consumption of at least 100 (80 for women) standard alcoholic drinks per month for the prior three years and active drinking at the time of study (HD). Multivariate analysis of covariance revealed no significant alcohol and HIV interactions ${ }^{[72]}$. However, the HD group was stratified into two groups: currently heavy drinkers (CHD - reporting an average of fewer than six drinks per occasion of drinking during the past week) and currently very heavy drinkers (CVHD - reporting an average of more than six drinks per occasion during the past week). Using the trichotomous variable for alcohol status (LD, CHD and CVHD), significant HIV-alcohol interactions were revealed. HIV-seropositive persons who were very heavy drinkers had lower processing speed, when compared to HIV-seronegative persons. Also, very heavy current drinking and HIV showed synergistic adverse effects on aspects of motor and visuomotor functioning.

Another study of 80 gay and bisexual men examined neuropsychological functioning among groups categorized by HIV status and history of alcohol abuse. HIV-seropositive and HIV-seronegative groups were analyzed separately; significant interaction effects for individual neuropsychological measures were revealed. No differences emerged in functioning within the HIV-seronegative group between those with and without a history of alcohol abuse. However, within the HIV-seropositive group, significant differences emerged between those with a history of alcohol abuse and those without such a history. Those who had a history of abuse showed higher levels of impairment in the areas of verbal IQ, verbal reasoning and reaction times $^{[73]}$.

One study examined the effects of HIV infection and chronic alcohol consumption on cerebral phosphorus metabolites in order to determine whether chronic alcohol abuse is a risk factor for the progression of neurological effects of HIV infection ${ }^{[74]}$. Ninety-six individuals were categorized into four groups: 15 HIVseronegative alcoholics, eight HIV-seronegative light/non-drinkers, $32 \mathrm{HIV}$-seropositive alcoholics and 41 HIV-seropositive light/non-drinkers. Magnetic resonance spectroscopy was used after magnetic resonance imaging to examine two brain volumes in the super white and subcortical gray matters. Chronic alcohol consumption and AIDS were associated with reduced white matter concentrations of phosphodiester (PDE) and phosphcreatine (PCr), compared with both HIV seronegative and clinically asymptomatic HIV seropositive subjects. A successive decrease of white matter PDE and PCr concentrations in the order of HIV seronegative light/non-drinkers, HIV-seronegative alcoholics, HIV-seropositive light/non-drinkers and HIV-seropositive alcoholics was found, providing evidence that adverse metabolic effects of HIV on the brain are exacerbated by chronic alcohol abuse.

Injecting drug use: Studies were identified that examined neuropsychological functioning, specifically testing for an interaction between injecting drug use (IDU) and HIV disease. In one study, 251 individuals were categorized into three groups: 75 asymptomatic HIV-seropositive IDUs, $97 \mathrm{HIV}$-seronegative IDUs and 79 HIV-seronegative non-IDUs. Five cognitive tests were administered and the results combined to calculate global cognitive impairment $(\mathrm{GCI})^{[75]}$. The outcomes indicated that the prevalence of GCI was significantly higher in HIV seropositive IDUs, than in either of the two groups of HIV-seronegative individuals. There were no differences between IDUs and non-IDUs who were HIV-seronegative. However, other studies examining the interaction effect of injecting drug use and HIV did not find a significant effect with respect to neuropsychological functioning or levels of agents such as choline and NAA ${ }^{[76-79]}$.

In one study, 113 individuals were divided into four groups: thirty-four seropositives who were all exIDUs, 33 seropositives (each of whom was in a methadone maintenance program), 19 seronegatives (each of whom had a history of drug use) and 27 seronegatives (none of whom had a history of drug use). All participants were administered a neuropsychological battery to assess neuropsychological efficiency. The seropositive individuals in methadone treatment had higher rates of damage and lower rates of execution in all test domains, compared to the remaining three groups. These findings suggest an additive effect of methadone on neuropsychological functioning among seropositive individuals; however, a history of injecting drug use did not have the same effect among the remaining HIVseropositive individuals in the sample ${ }^{[80]}$.

Other drugs: Other studies were identified that examined cognitive functioning. These studies controlled for HIV status and non-specific drug use, categorizing individuals who use various drugs as drug users. One study of 102 persons examined cognitive 
functioning in three groups (56 HIV-seropositive drug users, 19 HIV-seronegative drug users, 27 HIVseronegative non-drug users). Subjects underwent neuropsychological tests designed to explore cortical and subcortical function. HIV-seropositive drug users showed significantly lower performance scores than the HIV-seronegative groups. There were no differences between the two groups of HIV-seronegative persons. Among persons with HIV, progression of the disease (prior to AIDS) did not determine a decrease in intellectual performance. Instead, cognitive function was affected by the chronic and current use of illicit substances, with the subsequent decline in cognitive function among the HIV-seropositive group being attributed to a chronic use of illicit substances rather than HIV infection ${ }^{[81]}$.

A study of 42 African American women with a history of drug use examined neuropsychological functioning among four sub-groups based on HIV status (seronegative, asymptomatic seropositive, symptomatic seropositive, full-blown AIDS). Results revealed no evidence of HIV-related cognitive impairment in patients in the early stages of HIV; however, significant deficits in psychomotor processing and verbal recall emerged. The cognitive deficits in AIDS patients, however, were not related to the recentness of drug use ${ }^{[82]}$.

A study of 119 HIV-infected persons, categorized into two groups (67, at least 50 years of age and 42 who were 35 years of age or younger) examined neuropsychological functioning in various cognitive areas. While there was an age effect on neuropsychological effect, with older persons having more impairments, when participants with either a recent substance use disorder (including any one or combination of the following: alcohol, cannabis, cocaine, amphetamines, sedative, opiates, or hallucinogens) were removed from the analyses, the rates of in each group did not change substantially, suggesting no additive effect on neuropsychological impairments in this sample ${ }^{[83]}$.

In a study of $90 \mathrm{HIV}$-seropositive individuals, sensorimotor dysfunction was examined in three groups based on drug dependency (never dependent, formerly dependent-prior to one year and currently dependentduring the past year). Substances included were alcohol, cocaine and opiates. Analysis of variance revealed no significant effects of substance use-whether drug status was formerly dependent or currently dependent--on sensorimotor functioning ${ }^{[84]}$.

An early study examined neuropsychological functioning in 500 individuals (389 seropositives). While increased rates of impairment at each successive stage of HIV were found, impairment could not be explained by recreational drug or alcohol use, suggesting no additive effect of substance use in this sample ${ }^{[7]}$.
Future directions: A review of the research indicates that an abundance of studies have examined and documented the neuropsychological complications associated with HIV disease and various substances of abuse. However, the research focusing on the interaction or exacerbating effects of various substances of abuse on neuropsychological impairment among persons infected with HIV was much more limited. Of this research, the vast majority of the studies focused on the effects of methamphetamine use and HIV disease on neuropsychological complications. Research examining the possible interaction effects of other substances was scant. Among the available research, the study findings revealed mixed results with respect to HIV disease and substance abuse interactions. While some of the published research indicated an effect of substance use on neuropsychological complications among HIV-infected person, a number of studies found no such effect.

These findings, along with the neurological implications associated with HIV disease and substance abuse, suggest a number of avenues should be pursued in future research efforts. While the separate effects of HIV disease and substance use on brain structure and functioning have been well documented, more research is needed to address the effect of substance use on the severity and progression of HIV-associated psychoneurological complications. However, there is limited information at this time to indicate that a history of substance use either accounts for, or interacts with, HIV serostatus to facilitate the progression of neuropsychological impairment ${ }^{[5]}$. Expanding research in this area is important, considering the implications that comorbid substance abuse and HIV infection may have for treatment management, cognitive functioning and ultimate morbidity ${ }^{[15]}$. Evidence indicates that neuropsychological impairment and substance abuse are associated with an increased difficulty of medication adherence for HIV-infected persons; as such, there is a critical need for expanded research in this area ${ }^{[85]}$.

There seems to be a concerted need for the development of a comprehensive approach that could be used to study different substance of abuse, not only by type, but also by frequency of their abuse among HIV-infected individuals. The study should also include internal controls so that a maximum number of variables can be controlled. This would require the development of variety of neuropsychological tools that could address problems associated with a given study population. In addition, effort should also be concentrated on poly-drug abuse because this is becoming increasingly common; there is, at present, very little information on combined abuse. Longitudinal studies may allow a more powerful assessment of the neuropsychological effects of substance use and HIV disease. Such studies may help to answer the question as to whether aggressive substance abuse treatment can 
help decrease the neuropsychological complications associated with HIV disease, which may facilitate a "cognitive safety net" both for individuals with a history of substance abuse and current substance abusers who are living with HIV.

\section{ACKNOWLEDGEMENTS}

The authors would like to acknowledge Dr. Gregory Quirk, Ponce School of Medicine, for his comments. The authors would also like to acknowledge Mr. Bob Ritchie, Publications Officers, RCMI (2G12RR003050-21), Ponce School of Medicine, for editing the manuscript. One of us (AK) is supported by grants from NIDA (DA015013) and NIAAA (AA015045)

\section{REFERENCES}

1. UNAIDS, 2005. AIDS epidemic update December 2005. Joint United Nations Programme on HIV/AIDS, Geneva, Switzerland.

2. Hilsabeck, R. and P. Malek-Ahmadi, 2004. Neurobehavioral correlates of chronic hepatitis C. J. Psychopathol. Behav. Assess., 26: 203-210.

3. Wood S. and I. Grant, 2005. Neuropsychology of HIV. In: The Neurology of AIDS, (Eds. H.E. Gendelman, I. Grant, I.P. Everall, S.A. Lipton and S. Swindells), pp: 607-616. Oxford University Press, New York, NY.

4. Vanderploeg, R.D., 2000. Clinician's Guide to Neuropsychological Assessment. 2nd Edn. Lawrence Erlbaum Associates, Mahwah, NJ.

5. Grant, I., N. Sactor and J. McArthur, 2005. HIV neurocognitive disorders. In: The Neurology of AIDS, (Eds H.E. Gendelman, I. Grant, I.P. Everall, S.A. Lipton and S. Swindells), pp: 357-373. Oxford University Press, New York, NY.

6. Raines C., O Radcliffe and G.J. Treisman, 2005. Neurologic and psychiatric complications of antiretroviral agents. J. Assoc. Nurses AIDS Care, 16: 35-48.

7. Heaton, R.K., I. Grant, N. Butters, D.A. White, D. Kirson, J.H. Atkinson, J.A. McCutchan, M.J. Taylor, M.D. Kelly, R.J. Ellis, T. Wofson, R. Velin, T.D. Marcotte, J.R. Hesselink, T.L. Jernigan, J. Chandler, M. Wallace, I. Abramson and HIV Neurobehavioral Research Center, 1995. The HNRC 500 - neuropsychology of HIV infection at different disease stages. HIV Neurobehavioral Research Center. J. Int. Neuropsychol. Soc., 1: 231-51.

8. Ellis R.J., D.J. Moore, M.E. Childers, S. Letendre, J.A. McCutchan, T. Wolfson, S.A. Spector, K. Hsia, R.K. Heaton and I. Grant, 2002. Progression to neuropsychological impairment in human immunodeficiency virus infection predicted by elevated cerebrospinal fluid levels of human immunodeficiency virus RNA. Arch. Neurol., 59: 923-8.
9. Grant, I. and J.H. Atkinson, 1990. Neurogenic and psychogenic behavioral correlates of HIV infection. In: Immunologic Mechanisms in Neurological and Psychiatric Disease. (Ed., B.H. Waksman), pp: 291-304. Raven Press, New York.

10. Sacktor, N., 2002. The epidemiology of human immunodeficiency virus-associated neurological disease in the era of highly active antiretroviral therapy. J. Neurovirol., 8 (Suppl 2): 115-21.

11. Tozzi, V., P. Balestra, S. Galgani, P. Narciso, A. Sampaolesi, A Antinori, M. Guilianelli, D. Serraino and G. Ippolito, 2001. Changes in neurocognitive performance in a cohort of patients treated with HAART for 3 years. J. Acquir. Immune Defic. Syndr., 28: 19-27.

12. Valcour, V.G., C.M. Shikuma, M.R. Watters and N.C. Sactor, 2004. Cognitive impairment in older HIV-1 seropositive individuals: prevalence and potential mechanisms. AIDS, 18 (Suppl 1): S79S86.

13. Douaihy, A.B., R.J. Jou, T. Groske and I.M. Salloum, 2003. Triple diagnosis: dual diagnosis and HIV, Part 1. AIDS Read., 13: 331-41.

14. Block, R.I., W.J. Erwin and M.M. Ghoneim, 2002. Chronic drug use and cognitive impairments. Pharmacol. Biochem. Behav., 73: 491-504.

15. Basso, M.R. and R.A. Bornstein, 2000. Neurobehavioural consequences of substance abuse and HIV infection. J. Psychopharmacol., 14: 228-37.

16. Brust, J.C., 1993. Neurological Aspects Of Substance Abuse. Butterworth-Heinemann, Boston, MA.

17. Johnson, B.A., J.D. Roache, N. Ait-Daoud, C.L. Wallace, L.T. Wells, Y. Wang and M.A. Dawes, 2005. Effects of isradipine on cocaine-induced changes in cognitive performance in recently abstinent cocaine-dependent individuals. Int. J. Neuropsychopharmacol., 8: 549-56.

18. Jovanovski, D., S. Erb and K.K. Zakzanis, 2005. Neurocognitive deficits in cocaine users: a quantitative review of the evidence. J. Clin. Exp. Neuropsychol., 27: 189-204.

19. Kubler, A., K. Murphy and H. Garavan, 2005. Cocaine dependence and attention switching within and between verbal and visuospatial working memory. Eur. J Neurosci., 21: 1984-92.

20. Verdejo-Garcia, A.J., F. Lopez-Torrecillas, F. Aguilar de Arcos and M. Perez-Garcia, 2005. Differential effects of MDMA, cocaine and cannabis use severity on distinctive components of the executive functions in polysubstance users: a multiple regression analysis. Addict. Behav., 30: 89-101.

21. Bolla, K., M. Ernst, K Kiehl, M. Mouratidis, D. Eldreth , C. Contoreggi, J. Matochik, V. Jurian, J. Cadet, A. Kimes, F. Funderburk and E. London, 2004. Prefrontal cortical dysfunction in abstinent cocaine abusers. J. Neuropsychiatry Clin. Neurosci., 16: 456-64. 
22. Goldstein, R.Z., A.C. Leskovjan, A.L. Hoff, R. Hitzemann, F. Bashan, S.S. Khalsa , G.J. Wang, J.S. Fowler and N.D. Volkow, 2004. Severity of neuropsychological impairment in cocaine and alcohol addition: association with metabolism in the prefrontal cortex. Neuropsychologia, 42: 1447-58.

23. Fein, G., V. Di Sclafani and D.J. Meyerhoff, 2002. Prefrontal cortical volume reduction associated with frontal cortex function deficit in 6-week abstinent crack-cocaine dependent men. Drug Alcohol Depend., 68: 87-93.

24. Di Sclafani, V., M. Tolou-Shams, L.J. Price and G. Fein, 2002. Neuropsychological performance of individuals dependent on crack cocaine, or crackcocaine and alcohol, at 6 weeks and 6 months of abstinence. Drug Alcohol Depend., 66: 161-71.

25. Di Sclafani, V., H.W. Clark, M. Tolou-Shams, C.W. Bloomer, G.A. Salas, D. Norman and G. Fein, 1998. Premorbid brain size is a determinant of functional reserve in abstinent crack-cocaine and crack-cocaine-alcohol-dependent adults. J. Int. Neuropsychol. Soc., 4: 559-65.

26. Hoff, A.L., H. Riordan, L. Morris, V. Cestaro, M. Wieneke, R. Alpert R, G.J. Wang and N. Volkow, 1996. Effects of crack cocaine on neurocognitive function. Psychiatry Res., 60: 167-76.

27. Jernigan, T.L., A.C. Gamst, S.L. Archibald, C. Fennema-Notestine, M.R. Mindt, T.L. Marcotte, R.K. Heaton, R.J. Ellis and I. Grant, 2005. Effects of methamphetamine dependence and HIV infection on cerebral morphology. Am. J. Psychiatry, 162: 1461-72.

28. Kalechstein, A.D., T.F. Newton and M.Green, 2003. Methamphetamine dependence is associated with neurocognitive impairment in the initial phases of abstinence. J. Neuropsychiatry Clin. Neurosci., 15: 215-20.

29. Sim, T., S.L. Simon, C.P. Domier, K. Richardson, R.A. Rawson and W. Ling, 2002. Cognitive deficits among methamphetamine users with attention deficit hyperactivity disorder symptomatology. J. Addict. Dis., 21: 75-89.

30. Sjogren, P., L.L Christrup, M.A. Petersen and J. Hojsted, 2005. Neuropsychological assessment of chronic non-malignant pain patients treated in multidisciplinary pain centre. Eur. J. Pain, 9: 45362.

31. Davis P.E., H. Liddiard and T.M. McMillan, 2002. Neuropsychological deficits and opiate abuse. Drug Alcohol Depend., 67: 105-8.

32. Sjogren, P., A.B. Thomsen and A.K. Olsen, 2000. Impaired neuropsychological performance in chronic nonmalignant pain patients receiving longterm oral opioid therapy. J. Pain Symptom Manage., 19: 100-8.
33. O’Neill W.M., G.W. Hanks, P. Simpson, M.T. Fallon, E. Jenkins and K. Wesnes, 2000. The cognitive and psychomotor effects of morphine in healthy subjects: a randomized controlled trail of repeated (four) oral doses of dextropropoxyphene, morphine, lorazepam and placebo. Pain, 85: 20915.

34. Amir, T. and T. Bahri, 1994. Effect of substance use on visuographic function. Percept. Mot. Skills, 78: 235-41.

35. Verdejo-Garcia, A., I. Toribio, C. Orozco, K.L. Puente and M. Perez-Garcia, 2005. Neuropsychological functioning in methadone maintenance patients versus abstinent heroin abusers. Drug Alcohol Depend., 78: 283-8.

36. Gouzoulis-Mayfrank, E., T. Fischermann, M. Rezk, B. Thimm, G. Hensen and J Daumann, 2005. Memory performance in polyvalent MDMA (ecstasy) users who continue or discontinue MDMA use. Drug Alcohol Depend., 78: 317-23.

37. Gouzoulis-Mayfrank, E., K. Heekeren, A. Neukirch, M. Stoll, C. Stock, M. Obradovic and K.A. Kovar, 2005. Psychological effects of (S)ketamine and N,N-dimethyltryptamine (DMT): a double-blind, cross-over study in healthy volunteers. Pharmacopsychiatry, 38: 301-11.

38. Daumann, J., R. Schnitker, J. Weidemann, K. Schnell, A. Thron and E. Gouzoulis-Mayfrank, 2003. Neural correlates of working memory in pure and polyvalent ecstasy (MDMA) users. Neuroreport, 14: 1983-7.

39. Gouzoulis-Mayfrank, E., B. Thimm, M. Rezk, G. Hensen and J. Daumann, 2003. Memory impairment suggests hippocampal dysfunction in abstinent ecstasy users. Prog. Neuropsychopharmacol. Biol. Psychiatry, 27: 81927.

40. Gouzoulis-Mayfrant, E., B. Thelen, S. Maier, K. Heekeren, K.A. Kovar, H. Sass and M. Spitzer, 2002. Effects of the hallucinen psilocybin on covert orienting of visual attention in humans. Neuropsychobiology, 45: 205-12.

41. Gouzoulis-Mayfrank, E., J. Daumann, F. Tuchtenhagen, S. Pelz, S. Becker, J.H. Kunert, B. Fimm and H. Sass, 2000. Impaired cognitive performance in drug free users of recreational ecstasy (MDMA). J. Neurol. Neurosurg. Psychiatry, 68: 719-25.

42. Lundqvist, T., 2005. Cognitive consequences of cannabis use: comparison with abuse of stimulants and heroin with regard to attention, memory and executive functions. Pharmacol. Biochem. Beh., 81: 319-30.

43. Solowij, N., R.S. Stephens, R.A. Roffman, T. Babor, R. Kadden, M. Miller, K. Christiansen, B. McRee, J. Vendetti and Marijuana Treatment Project Research Group, 2002. Cognitive functioning of long-term heavy cannabis users seeking treatment. J. Am. Med. Assoc., 287: 1123-31. 
44. Solowij, N., P.T. Michie and A.M. Fox, 1995. Differential impairments of selective attention due to frequency and duration of cannabis use. Biol. Psychiatry, 37: 731-9.

45. Parrott, A.C., E. Gouzoulis-Meyfrank, J. Rodgers and N. Solowij, 2004. Ecstasy/MDMA and cannabis: The complexities of their interactive neuropsychobiological

Psychopharmacology, 18: 572-5.

46. Daumann, J., G. Hensen, B. Thimm, M. Rezk, B. Till and E. Gouzoulis-Mayfrank, 2004. Selfreported psychopathological symptoms in recreational ecstasy (MDMA) users are mainly associated with regular cannabis use: further evidence from a combined crosssectional/longitudinal investigation. Psychopharmacology, 173: 398-404.

47. Pentney, R., 2000. Brain drain: alcohol's effect on the aging brain. UB Res. Quart., 10: 1-2.

48. Crews, F.T., M.A. Collins, C. Dlugos, J. Littleton, L. Wilkins, E.J. Neafsey, R. Pentney, L.D. Snell, B. Tabakoff, J. Zou and A. Noronha, 2004. Alcohol-induce neurodegeneration: when, where and why? Alcohol. Clin. Exp. Res., 28: 350-64.

49. Sullivan, E.V., A.J. Harding, R. Pentney, C. Dlugos, P.R. Martin, M.H. Parks, J.E. Desmond, S.H. Chen, M.R. Pryor, E. De Rosa and A. Pfefferbaum, 2003. Disruption of frontocerebellar circuitry and function in alcoholism. Alcohol. Clin. Exp. Res., 27: 301-9.

50. Parsons, O.A. and S.J. Nixon, 1998. Cognitive functioning in sober drinkers: a review of the research since 1986. J. Stud. Alcohol, 59: 180-90.

51. Parsons, O.A., 1998. Neurocognitive deficits in alcoholics and social drinkers: a continuum? Alcohol. Clin. Exp. Res., 22: 954-61.

52. Nixon, S.J., R.D. Tivis, M.R. Jenkins and O.A. Parsons, 1998. Effects of cues on memory in alcoholics and controls. Alcohol. Clin. Exp. Res., 22: 1065-9.

53. Tivis, R., W.W. Beatty, S.J. Nixon and O.A. Parsons, 1995. Patterns of cognitive impairment among alcoholics: are there subtypes? Alcohol. Clin. Exp. Res., 19: 496-500.

54. Rippeth, J., C.L. Carey, S.P. Woods, R.K. Heaton, I. Grant and HNRC Group, 2004. Cognitive, psychiatric and medical predictors of relapse in HIV+ methamphetamine abusers. J. Int. Neuropsychol. Soc., 10 (Suppl S1): 20.

55. Margolin, A., S.K. Avants, L.A. Warburton and K.A. Hawkins, 2002. Factors affecting cognitive functioning in a sample of human immunodeficiency virus-positive injection drug users. AIDS Patient Care STDS, 16: 255-67.

56. Gonzalez, R., J.D. Rippeth, C. Carey, R.K. Heaton, D.J. Moore, B.C. Schweinsburg, M. Cherner and I. Grant, 2004. Neurocognitive performance of methamphetamine users discordant for history of marijuana exposure. Drug Alcohol Depend., 76: 181-90.
57. Waldrop-Valverde, D., R.L. Ownby, F.L. Wilkie, A. Mack, M. Kumar and L Metsch, 2006. Neurocognitive aspects of medication adherence in HIV-positive injecting drug users. AIDS Behav., 17: [Epub ahead of print].

58. Rippeth, J., D. Moore, R. Gonzalez, L. Dawson, R. Marcotte, R. Heaton, I. Grant and HNRC Group, 2001. Neuropsychological effects of HIV infection and methamphetamine dependence. J. Int. Neuropsychol. Soc., 7: 149.

59. Rippeth, J., R.K. Heaton, C. Carey, T. Marcotte, D.J. Moore, R. Gonzalez and I. Grant, 2002. Effects of HIV infection and methamphetamine on specific cognitive domains. J. Int. Neuropsychol. Soc., 8: 188.

60. Rippeth, J.D., R.K. Heaton, C.L. Carey, T.D. Marcotte, D.J. Moore, R.Gonzalez, T. Wolfson, I. Grant and HNRC Group, 2004. Methamphetamine dependence increase risk of neuropsychological impairment in HIV infected persons. J. Int. Neuropsychol. Soc., 10: 1-14.

61. Sadek, J.R., R.K. Heaton, S.P. Woods, J.R. Rippeth, M. Cherner, C. Young, D. Lazzaretto, I. Grant and HNRC Group, 2004. The impact of depression on self-reported impairment in HIV and methamphetamine use. J. Int. Neuropsychol. Soc., 10 (Suppl S1): 197.

62. Cherner, M., R. Ellis, T. Marcotte, R. Heaton, I. Grant and HNRC Group, 2001. Learning impairments on the California Verbal Learning Test are related to methamphetamine abuse and HIV status. J. Int. Neuropsychol. Soc., 6: 232.

63. Hayes, M.P., R.J. Ellis, L. Ryan, M.E. Childers, I. Grant, T. Wolfson, S. Archibald, T.L. Jernigan and HNRC Group, 2001. Elevated cerebrospinal fluid quinolinic acid levels are associated with regionspecific cerebral volume loss in HIV infection. Brain, 124: 1033-42.

64. Taylor, M.J., B.C. Schweinsburg, O.M. Alhassoon, G.G. Brown, R.K. Heaton, I. Grant and HNRC Group, 2002. Concordance of MR spectroscopic and neuropsychological deficits in HIV and methamphetamine dependence. J. Int. Neuropsychol. Soc., 8: 314.

65. Grant, I., R.K. Heaton, L.K. Dawson and T.D. Marcotte, 1999. Abuse of methamphetamine and cocaine may enhance HIV associated neurotoxicity. Int. J. NeuroPharmacol., 2 (Suppl 1): S172.

66. Levine, A.J., D.J. Hardy, E. Miller, S.A. Catellon, D. Longshore and C.H. Hinkin, 2006. The effect of recent stimulant use on sustained attention in HIVinfected adults. J. Clin. Exp. Neuropsychol., 28: 29-42.

67. Taylor, M.J., O.M. Alhassoon, B.C. Schweinsburg, J.S. Videen, I. Grant and HNRC Group, 2000. MR spectroscopy in HIV and stimulant dependence. J. Int. Neuropsychol. Soc., 6: 83-85. 
68. Meyerhoff, D.J., 2001. Effects of alcohol and HIV infection on the central nervous system. Alcohol Res. Health, 25: 288-98.

69. Huang, W., G.E. Alexander, E.M. Daly, H. Umesha Shetty , J.S. Drasuski, S.I. Rapoport and M.B. Schapiro, 1999. High brain myo-inositol levels in the predementia phase of alzheimer's disease in adults with Down's Syndrome. Am. J. Psychiatry, 156: 1879-86.

70. Durvasula, R.S., H.F. Myers, P. Satz, E.N. Miller, H. Morgenstern, M.A Richardson, G. Evans and D. Forney, 2000. HIV-1, cocaine and neuropsychological performance in African American men. J. Int. Neuropsychol. Soc., 6: 32235.

71. Cristiani, S.A., N.D. Pukay-Martin and R.A. Bornstein, 2004. Marijuana use and cognitive function in HIV-infected people. J. Neuropsychiatry Clin. Neurosci., 16: 330-335.

72. Rothlind, J.C., T.M. Greenfield, A.V. Bruce, D.J. Meyerhoff, D.L Flenniken, J.A. Lindgren and M.W. Weiner, 2005. Heavy alcohol consumption in individuals with HIV infection: effects on neuropsychological performance. J. Int. Neuropsychol. Soc., 11: 70-83.

73. Green, J.E., R.V. Saveanu and R.A Bornstein, 2004. The effect of previous alcohol abuse on cognitive function in HIV infection. Am. J. Psychiatry, 161: 249-254.

74. Meyerhoff, D.J., S. MacKay, D. Sappey-Marinier, R. Deicken, G Calabrese, W.P Dillion, M.W. Weinger and G. Fein, 1995. Effects of chronic alcohol abuse and HIV infection on brain phosphorus metabolites. Alcohol. Clin. Exp. Res., 19: 685-92.

75. Starace, F., C. Baldassarre, V. Biancolilli, M. Fea, G. Serpelloni, L. Bartoli and M. Maj, 1998. Early neuropsychological impairment in HIVseropositive intravenous drug users: evidence from the Italian Multicentre Neuropsychological HIV Study. Acta Psychiatr. Scand., 97: 132-8.

76. Vazquez-Justo, E., M. Rodriguez Alvarez and J. Carro Ramos, 2003. Neuropsychological performance in HIV/AIDS intravenous drug users. J. Clin. Exp. Neuropsychol., 25: 852-65.
77. Wisniewski, A.B., S. Apel, O.A. Selnes, A. Nath, J.C. McArthur and A.S. Dobs, 2005. Depression symptoms, quality of life and neuropsychological performance in HIV/AIDS: the impact of gender and injection drug use. J. Neurovirol., 11: 138-143.

78. Selnes, O.A., N. Galai, J.C. McArthur, S. Cohn, W. Royal, D. Esposito and D. Vlahov, 1997. HIV infection and cognition in intravenous drug users: long-term follow-up. Neurology, 48: 223-30.

79. Jarvik, J.G., R.E. Lenkinski, A.J. Saykin, A. Jaans and I. Frank. 1996. Proton spectroscopy in asymptomatic HIV-infected adults: initial results in a prospect cohort study. J. Acquir. Immune Defic. Syndr. Hum. Retrovirol., 13: 247-53.

80. Failde Garrido, J.M., J. Lopez Castro, V. Fernandez Rodriquez and R. Fernandez Rodriquez, 2005. HIV-infection, use of drugs and neuropsychologic efficiency. An. Med. Interna, 22: 569-74.

81. Grassi, M.P., F. Clerici, C. Perin, C. Zocchetti, M. Borella, A. Cargnel and A. Mangoni, 1995. HIV infection and drug use: Influence on cognitive function. AIDS, 9: 165-70.

82. Mason, K.I., A. Campbell, P. Hawkins, S. Madhere, K. Johnson and R. Takushi-Chinen, 1998. Neuropsychological functioning in HIVpositive African American women with a history of drug use. J. Nat. Med. Assoc., 90: 665-74.

83. Cherner, M., R.J. Ellis, D. Lazzaretto, C. Young, M.R. Mindt, J.H. Atkinson, I. Grant, R.K Heaton and HNRC Group, 2004. Effects of HIV-1 infection and aging on neurobehavioral functioning: preliminary findings. AIDS, 18 (Suppl 1): S27-S34.

84. Bauer, L.O., N.A. Ceballos, J.D. Shanley and L.I Wofson, 2005. Sensorimotor dysfunction in HIV/AIDS: effects of antiretroviral treatment and comorbid psychiatric disorders. AIDS, 19: 495502 .

85. Hinkin, C.H., D.J. Hardy, K.I. Mason, S.A. Castellon, R.S. Durvasula, M.N Lam and M. Stefaniak, 2004. Medication adherence in HIVinfected adults: effect of patient age, cognitive status and substance abuse. AIDS, 18 (Suppl 1): S19-S25. 